\title{
АДМИНИСТРАТИВНЫЕ МЕТОДЫ ПРОТИВОДЕЙСТВИЯ «ЦВЕТНЫМ РЕВОЛЮЦИЯМ»
}

\author{
Карпов Олег Вячеславович \\ Старший преподаватель, Владимирский филиал \\ PAHХUГC
}

ADMINISTRATIVE METHODS OF COUNTERING "COLOR REVOLUTIONS"

O. Karpov

N. Kuchin

Summary. In the 21st century, extremism, as a phenomenon of modern reality, is increasingly attracting the attention of state bodies, whose main goal is to protect law and public order. Often, offenses and crimes in the field of extremism become resonant in society for the reason that a certain number of initiated and investigated administrative and criminal cases on them seem questionable in terms of legality, objectivity and validity of bringing a person to one or another measure of responsibility. In this paper, the authors attempted to analyze and study administrative methods of countering such a phenomenon as the "color revolution".

Keywords: extremism, color revolution, public order, digitalization, internet resources, administrative offense, administrative proceedings.

B настоящее время феномен «экстремизма», на фоне нестабильной политико-экономической, а в следствии этого социальной обстановки проявляется в совершенно новых аспектах. Если буквально десять лет назад, общество «контактировало» с феноменом «экстремизм» в его радикальной форме -терроризм, и сопутствующим ему формах оправдание и пропаганда экстремисткой деятельности, публичные призывы к экстремизму и терроризму, то в настоящее время появляются совершенно иные его проявления. Экстремизм многолик: религиозный, идеологический, политический, он представляет серьезную угрозу стабильности и развитию общественных институтов не только в границах отдельного государства, но и в мировом масштабе. Поэтому борьба с ним, противодействие экстремизму, минимизация его последствий до социально-неопасного уровня, на наш взгляд, является первостепенной задачей правоохранительных органов и государственных институтов как отдельно взятого государства, так и всей международно-правовой системы в целом.
Суть данного исследования заключается в попытке анализа применения административного метода противодействия экстремизма к его наиболее распространенному (особенно в последнее время) проявлению - «иветная революиия». «Цветная революция» - специфический тип политической технологии, переходящий в деструктивно - направленную. Основная ее цель заключается в «мягкой, ненасильственной» смене институтов власти в государстве. Внешнее выражение осуществления цветной революции чаще всего происходит через серию небольших по масштабу, но интенсивно повторяющихся за короткий временной промежуток уличных массовых протестов населения, которые в итоге приводят к смене правящий элиты как в отдельно взятой территории, так и в рамках целого государства. Говоря о цветных революциях, стоит вкратце отметить на каких принципах они строятся, какие технологии заложены в основу их реализации. Основной, на наш взгляд, принцип заключается в том, что цветные революции чаще всего организуются не радикально настроенной оппозицией, или правыми 
силами, а частью старой политической элиты, которая в предыдущие стадии была «у руля» государственного управления. Цветные революции сложно провести в стране, существующий в авторитарном режиме, но в полудемократических странах, где процент легитимно действующий власти и оппозиции практически одинаков - революция возможна. Кульминацией цветных революций являются выборы, когда оппозиция задолго до их конца объявляет о своей победе, а любые иные данные, даже достоверные, выдает за фальсификацию и распространяет такие сведения среди широкого неопределенного круга лиц. Главным механизмом воздействия на государственные институты становится проведение бесконтрольных массовых демонстраций и несанкционированных митингов, в крайних случаях - захват административных центров, блокирование зданий правительства, посольств, силовых структур.

Описывая этапы действия цветной революции, стоит отметить три стадии ее развития, и подчеркнуть, что предотвращение реализации «цветных технологий» на ранних этапах - наиболее эффективный метод противодействия. На первой стадии организаторы цветной революции чаще всего устраивают символические, целенаправленные акции протеста, создают общественные комитеты - «однодневки» якобы для решения важных социальных проблем. Цель на данной стадии - создать коллективный миф среди населения, преимущественно людей молодого и среднего возрастов о том, что «власть не является легитимной и законной». Именно оценка организаторами состояния антиправительственных настроений в обществе; оценка потенциально-заряженного контингента, который готов стать основной движущей силой протестов, является платформой для второго этапа, основной мотив которого заключается в указании как можно большему количеству людей на скрытые или явно-выраженные недостатки действующий власти. Стоит подчеркнуть очень важный момент, состоящий в том, что если, каким-либо образом на второй стадии проведения цветной революции обнаруживается наличие устойчивых «подрывных» элементов в государственной структуре в целом, и в отдельных государственных органах в частности, данный факт может сыграть ключевую роль в процессе формирования предпосылок к революционной обстановки даже в самой политически устойчивой и социально развитой стране. На третьем этапе непосредственно происходит «мягкое свержение» власти, хотя сами методы далеко не являются ненасильственными. Здесь стоит вспомнить события на Украине 2014 года или недавнюю ситуацию в Белоруссии, где анархически устроенные акции толпы сопровождались повсеместными массовыми нарушениями общественного порядка, приведшими, в том числе, и к трагическим последствиям. В последние годы цветные революции приобретают новую, информационную форму, используя «бреши» в системе повсеместной «цифровизации» социума. Стоит отметить такую разновидность цветной революции, как twitter-революция, когда пропаганда населения ведется через социальные сети и мессенджеры, что является наиболее благоприятной инфраструктурой распространения экстремистских и антиправительственных идей среди неограниченного круга лиц по всему миру. Такой системой может стать любая информационно-социальная площадка, позволяющая собирать, распространять и хранить данные в информационно-телекоммуникационной сети «Интернет». Также феномен «сети» распространяется и на общественные институты, где через идеологическую призму происходит подмена ценностей отдельно взятого публичного социального коллектива, формируется определенное общественное мнение, которое потом и становится «толчком» к началу протестных акций. Именно вызвать противоречия в восприятии индивидом мира, указать ему на очевидную разницу между тем, чему «учат в школе» и тем, с чем ему приходится каждый день сталкиваться в реальной жизни, а после направить его на публичные выступления и рассказы о своем «просветлении» - одна из ключевых целей, добившись которых организаторы цветных технологий уходят в тень. Ведь такому человеку, которому все «объяснили и рассказали», показали слабости власти и вселили чувство собственной важности и способности «мягким насилием» изменить ситуацию, больше не нужен руководящий центр управления. Он сам найдет тех, кто разделит с ним новую точку зрения, а после потеряет грань между маргинальным и преступным поведением; а акции «белых ленточек и красных роз» превратятся в создание организованных преступных групп и сообществ, единственной целью которыхвведение общества в состоянии анархии, дестабилизация и дискредитация государства как такового.

Bсе вышеописанные примеры явно указывают на экстремистскую основу цветных революции, порою переходящую в террористическую, когда организаторы понимают, что «методы создания мира во всем мире» уже не работают, и начинается серия локальных актов терроризма. Из этого следует, что противодействие, минимизация последствий и ликвидация такой разновидности современного экстремизма - одна из важнейших задач правоохранительной системы государства. Основными методами противодействия являются: нормативно-правовой, информационный, силовой и административный. На этом методе мы и остановимся, выделив его большую, на наш взгляд, эффективность по сравнению с другими.

Административные методы обладают намного большей оперативностью чем нормативно-правовые и силовые, позволяя в достаточно короткий срок решать 
широкий спектр задач минимизации проявления «цветных технологий» в обществе еще на этапе их подготовки. Цветная революция - это не естественная реакция людей на процессы, протекающие в социуме, но целенаправленно созданная ситуация, направленная на хаотизацию социальной обстановки. Одним из главных вопросов в сфере профилактических мер «цветных революций» является вопрос о том, кто, сколько и каких ресурсов предоставил, а главное: кто собирается ими воспользоваться. Парадоксальное шоковое впечатление, которое на власть производили действия «сплоченной думающей» толпы, заключается в ошибочном представлении об том, как должен действовать противник. Если подтвержденная историческими примерами практика показывает, что оппонент чаще всего скрывает сведения о себе, старается сохранить все в тайне и любые открытые проявления вероятнее всего «уловка», то в мире социальных сетей и интернет-форумов, наоборот: организаторы цветных революций открыто пишут об этом, ставя целью наиболее массовое распространение информации. Получается: власть играет в «покер», видя в действиях оппозиции скрытую информацию и мотивы, а последняя, наоборот: предпочитает «шахматы», предоставляя на всеобщее обозрение не только данные о себе, но и о своих планах и действиях. Таким образом, принять открытость, как неизбежную данность, и также открыто противостоять - вероятно наиболее разумное решение в организации мер противодействия.

Основной ресурс цветных революций - люди, и поэтому наиболее эффективным методом поведения властей, на наш взгляд, является метод-мониторинга сетевых интернет-ресурсов. Так как люди чаще всего собраны в сетевые структуры, целесообразным является проведение данного мониторинга с целью понимания качественного и количественного состава групп, оценка масштаба деятельности.

Административные методы противодействия активно используются, в частности органами прокурорского надзора, деятельность которых регулируется различными нормативно-правовыми актами, в том числе и Федеральным законом от 28.12.2013 № 398-Ф3 «О внесении изменений в Федеральный закон «Об информации, информационных технологиях и о защите информации», основная цель которого - регламентация внесудебного порядок ограничения доступа к потенциально вредоносным интернет-ресурсам [5]. Динамика применения данного закона на данный момент положительна. За неполный 2020 год Роскомнадзором по требованию органов прокуратуры было заблокировано более 3000 тысяч экстремистских сайтов, а также приостановлена деятельность более 500 веб-ресурсов, созданных для пропаганды и оправдания терроризма, а также сбору денежных средств на электронные кошельки для отправки воюющим боевикам в Сирию, на Северный Кавказ.

С каждым годом, начиная с 2014 года, все больше растет конфликт между провайдерами интернет хостингов и представителями правоохранительных органов. Суть конфликта заключается в том, что провайдеры отказываются блокировать сайты, объясняя это упущенной выгодой, и именно здесь эффективность административных мер по сравнению с другими выглядит наиболее предпочтительнее.

По каждом случаю уклонения провайдером от блокировки вредоносного интернет-ресурса, ограничению доступа и удаления информации с такого ресурса, органы прокуратуры оперативно должны собрать всю необходимую информацию для решения вопроса о возбуждении дела об административном правонарушении, предусмотренном ст. 20.29. КоАП РФ - «Производство и распространение экстремистских материалов» [2]. Говоря об объективной стороне правонарушения, стоит отметить, что последнюю составляет деятельность по распространению экстремистских материалов, их производству и хранению в целях распространения. Обязательными признаками объективной стороны рассматриваемого состава административного правонарушения являются признание информационных материалов экстремистскими на основании решения суда и включение их в федеральный список экстремистских материалов, составляемый Министерством юстиции РФ и подлежащий опубликованию.

Производство по данному правонарушению должно быть произведено строго в соответствии с главой 28 КоАП РФ, в ходе которого правоохранительные органы после исследования всех собранных фактов должны прийти к выводу о целесообразности возбуждения административного дела.

Остановимся на некоторых вопросов, касающихся проведению административного расследования по правонарушениям в сфере экстремизма.

Так как, в настоящее время наблюдается отсутствие стабильной судебно-следственной практики по делам об административных правонарушениях, предусмотренных ст. 20.29, 20.3.1 КоАП РФ, возникает проблема по выявлению и установлению определенных сформировавшихся принципов, применения административного законодательства в исследуемой нами области. К примеру, целью введения в 2018 году в КоАП ст. 20.3.1, являлось стремление законодателя к декриминализации статьи 282 УК РФ, осужденных по которой с каждый годом, становилось в вдвое больше, чем в предыдущих. В частности, данная статья уменьшала суровую уголовную ответственность, которая могла наступить даже 
после первой публикации экстремистских материалов, с другой сохраняла ответственность за такую публикацию в сети Интернет. Проблемным моментом является то, что даже согласно законам юридической техники, невозможно критерии, заложенные в ч. 1 ст. 282 УК РФ полностью с сохранением исходного смысла нормы, перенести в административно-деликтное законодательство. Только после окончательного формирования устойчивой судебной практики по применению административного законодательства за экстремистские и сепаратистские правонарушения возможно выработать критерии и принципы, которые будут положены в основу производства по делам об административных правонарушениях в исследуемой нами сфере. В настоящее время административная ответственность за экстремистскую деятельность прямо предусмотрена ст. 15.27 «Неисполнение требований законодательства о противодействии легализации (отмыванию) доходов, полученных преступным путём, и финансированию терроризма», ст. 20.3 «Пропаганда и публичное демонстрирование нацистской атрибутики или символики», ст. 20.28 «Организация деятельности общественного или религиозного объединения, в отношении которого принято решение о приостановлении его деятельности», ст. 20.29 «Производство и распространение экстремистских материалов», ст. 20.3.1 «Возбуждение ненависти либо вражды, а равно унижение человеческого достоинства» [2]. Все вышеперечисленные правонарушения предшествует уголовным преступлениям экстремистского характера и свидетельствует о возможности трансформации, по критерию степени общественной опасности первых во вторые. Существующее Постановлении Пленума Верховного Суда РФ от 8 июня 2011 г. № 11 «О судебной практике по уголовным делам о преступлениях экстремистской направленности» теоретически хоть и разграничивает уголовные преступления от административных правонарушений, но все равно допускает «конкуренцию» норм в данной сфере [7]. К примеру, в нем сказано: «вопрос о том, является ли массовое распространение экстремистских материалов, включенных в опубликованный федеральный список экстремистских материалов, преступлением, предусмотренным ст. 282 УК РФ, или административным правонарушением (ст. 20.29 Кодекса Российской Федерации об административных правонарушениях), должен разрешаться в зависимости от направленности умысла лица, распространяющего указанные материалы[7]. А как известно и в административной и уголовной практике расследования, доказывания умысла, а тем более разграничение характера и степени его направленности у лица, достаточно сложное следственное действие сопровождающиеся сложными комплексными психолого-психиатрическими судебными экспертизами и иными процессуальными действиями. На практике, очень часто возникает ситуация, когда уголовная ответственность возможна за призывы к осуществлению административного правонарушения экстремистского характера. Возникновение таких правовых пробелов - нежелательно, и их следует устранять путем разъяснения и конкретизации содержания публичных призывов к осуществлению экстремистской деятельности и пропаганде экстремизма.

Данные рассуждения служат примером того, что в настоящие время, когда судебная практика еще не устойчива, процедура проведения производства по делам об административных правонарушениях в сфере экстремизма детально не разработана и не регламентирована, административные методы, являются единственным эффективным решением в области противодействиях экстремизму, находясь в наряду с нормативными, информационными и силовыми, в чем то опережая их в оперативности, но и уступая им в системности и законодательной закрепленности.

Таким образом, подводя итог вышесказанному, мы приходим к выводу, что экстремизм в настоящее время все чаще «контактирует» с обществом, через проведение его сторонниками «цветных революций», организацию несанкционированных митингов и пикетов, призванных в своей цели дестабилизировать государственные институты и посеять анархию в обществе. Административные методы противодействия таким явлениям, эффективны прежде всего тем, что на практике способны на начальных этапах и стадиях, когда только организовывается цветная революция, или распространяется экстремистки направленный материал неограниченному контингенту, минимизировать данные противоправные проявления путем применения всего инструментария законодательно в них заложенного: от мониторинга органами прокуратуры вредоносных интернет ресурсов, до принятия мер по ограничению доступа к информационным ресурсам, содержащим и распространяющим информацию экстремисткой направленности. Уверены, что когда на практике будет произведено разделение компетенции административных и уголовных норм в сфере экстремизма и его проявлений, расширены составы правонарушений и преступлений, путем введения составов за призывы к проведению «цветных революций», применению когнитивных технологий, направленных на возбуждение ненависти или вражды по полу расе, национальности или иным признакам, сформируется устойчивая судебная практика, а роль и значение административной ответственности для лиц преступивших закон действительно будет играть превентивную меру предупреждения, административные методы противодействия и профилактики, станут наиболее востребованными, но уже в качестве усиления законодательно регламентируемой процедуры создания и реализации нормативных-правовых актов. 
ЛИТЕРАТУРА

1. Конституция Российской Федерации» (принята всенародным голосованием 12.12 .1993 с изменениями, одобренными в ходе общероссийского голосования 01.07.2020) // Российская газета, № 144, 04.07.2020.

2. «Кодекс Российской Федерации об административных правонарушениях» от 30.12.2001 № 195-Ф3 (ред. от 22.08.2021) // Российская газета, № 256, 31.12.2001.

3. «Уголовный кодекс Российской Федерации» от 13.06.1996 N63-Ф3 (ред. от 12.07.2021) // СЗ РФ. — 1996. — № 25.— ст. 2954.

4. Федеральный закон «0 противодействии экстремистской деятельности» от 25.07.2002 № 114-Ф3 (ред. от 12.07.2021) // Российская газета № 138-139, 30.07.2002.

5. Федеральный закон от 28.12.2013 N398-Ф3 «0 внесении изменений в Федеральный закон «0б информации, информационных технологиях и 0 защите информации» // СЗ РФ. - 2013. — № 52 (ч. 1.) - ст. 6963.

6. Постановление Пленума Верховного суда РФ от 28 июня 2011 г. N11 “0 судебной практике по уголовным делам о преступлениях экстремистской направленности".

7. Приказ Генерального прокурора от 21.03.2018 № 156 «0б организации прокурорского надзора за исполнением законодательства о противодействии экстремистской деятельности».

8. Агапов П.В. Экстремизм: стратегия противодействия и прокурорский надзор // монография. Акад. Ген. Прокуратуры Рос. Федерации.- М.,2015.- - С. 428.

9. Клейменов М.П. Соотношение административных и уголовных правонарушений экстремистской направленности // «Вестник Омского университета». Серия «Право», 2012.—№ 2 (31) - С. 176-177.

( ) Карпов Олег Вячеславович ( okarp67@mail.ru ), Кучин Никита Сергеевич ( nik.antipov.2000@inbox.ru ).

Журнал «Современная наука: актуальные проблемы теории и практики»

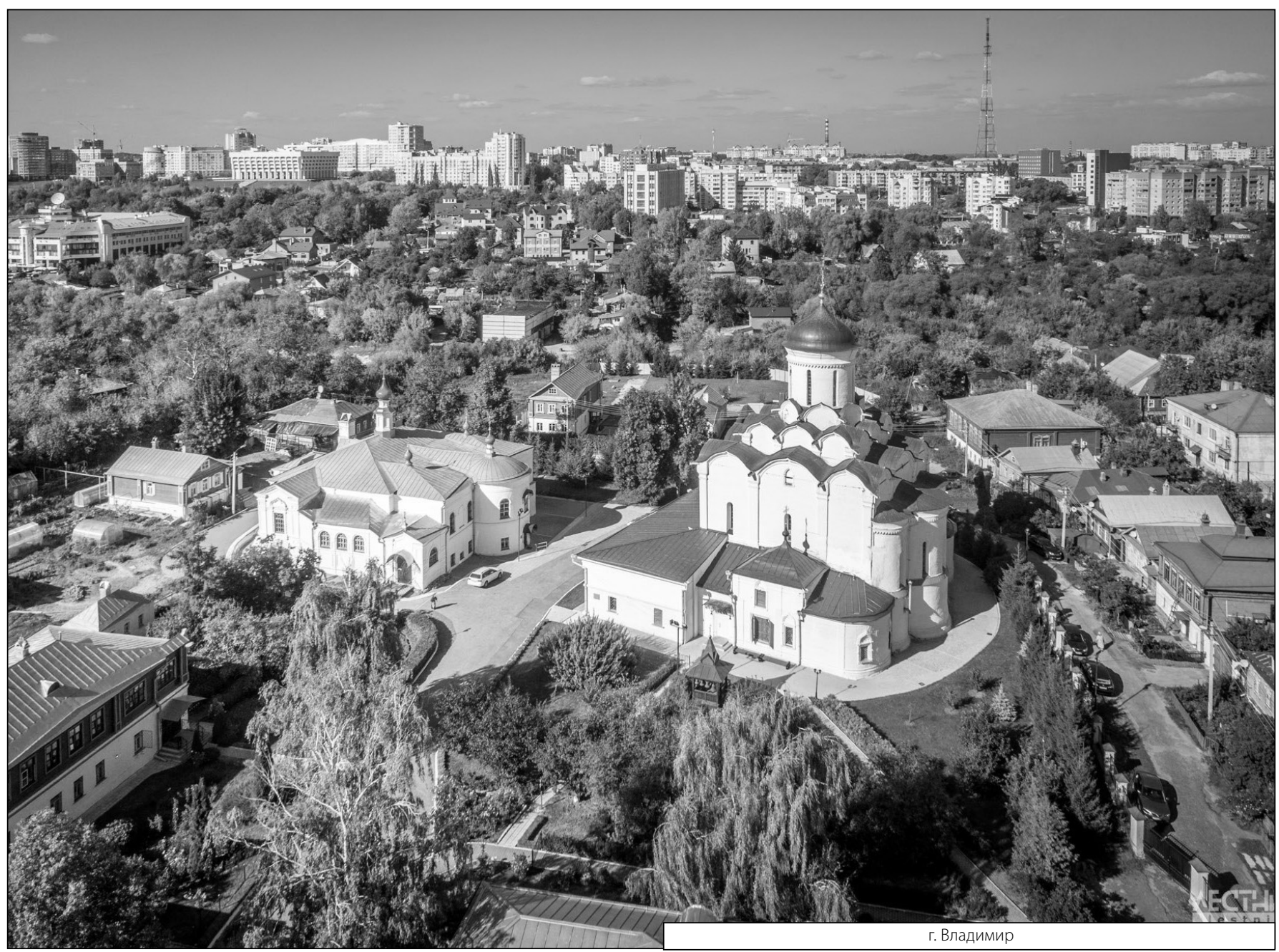

